\title{
Research on the Current Situation and Countermeasures of Economics Course Teaching in Applied Undergraduate Colleges under the Background of MOOC
}

\author{
Min Zhou \\ Finance and Accounting College of AnHui SanLian University, AnHui HeFei, 230601, China
}

Keywords: MOOC; Economics; Teaching

\begin{abstract}
Based on the analysis of the current teaching situation of economics courses in application-oriented universities, the paper pointed out MOOC resources can broaden the teaching content, enrich teaching methods, help teachers and students interact and conform to students' learning characteristics. MOOC teaching practice generally exist problems of poor quality of teaching design, low attention of students and low completion rate of courses. It is suggested to construct high-quality MOOC resources in economics, design appropriate classroom teaching and MOOC integration mode, and enhance online and offline discussions of MOOC.
\end{abstract}

\section{Introduction}

MOCC (abbreviation of Massive Open Online Course) is a large-scale online open course. It was led by international famous schools such as Harvard and MI in 2012 and swept the world in one or two years. In 2013, domestic first-class colleges and universities announced their participation in the ranks of the class, and began a new era of Chinese motto. The influence of the use of MOOC resources on the teaching of colleges and universities has achieved certain results in theory. For example, Huang Xiaojie uses hypothesis testing method to conclude that the combination of MOOC online courses and local actual "economic mathematics" teaching is an effective way to improve teaching quality ${ }^{[1]}$. Hao Lianke first discussed the definition and theoretical basis of hybrid learning, and secondly designed the hybrid learning model based on MOOC environment. Finally, the application effect of the model was investigated and analyzed [2]. Tang Huiyun's questionnaire survey results show that the teaching of MOOC network sharing courses helps to optimize teaching resources, enrich and improve teaching forms, and achieve better learning results in more areas ${ }^{[3]}$. Some scholars in China have carried out research on the teaching reform of economics courses. Wang Sujun discovered through investigation that there are many problems in the course of actual teaching in the course of "Western Economics", and there are embarrassing situations in which teachers are difficult to teach and students are difficult to learn. Out of innovative reform measures, and establish a sound curriculum quality assurance mechanism ${ }^{[4]}$. Zhou Xiaoyue conducted a questionnaire survey on students of financial mathematics who have studied Western economics at different levels. Through the analysis and analysis of the data, some ideas were put forward for the teaching reform of Western economics in financial mathematics ${ }^{[5]}$.

The existing research shows that the effective integration of offline teaching and online MOOC data has a positive effect on the teaching effect. Although this integration is in its infancy, it satisfies the learning habits and needs of contemporary college students in the information age. Compared with the application of MOOC in other disciplines, the teaching of economics courses based on MOOC resources is almost in the blank. The economics course is a core professional foundation course offered by the economic management major. The quality of its teaching directly affects the study of other professional courses. Due to the large number of students studying in economics, the basics of students in different majors are different. Each major has different requirements for economics. How to use MOOC's hybrid teaching model to improve the overall learning of economics Quality has become an urgent problem to be solved. Therefore, based on the analysis of the current teaching status of economics courses in applied undergraduate colleges, this study explores the advantages and disadvantages of MOOC teaching in practice, and gives targeted 
optimization of MOOC in economics. The countermeasures of teaching application, in order to promote the effective integration of MOOC resources and economics teaching.

\section{Teaching Status Quo of Economics Courses in Applied Undergraduate Colleges}

The content of the economics course mainly includes microeconomics and macroeconomics. Some universities only open some of them, or cover both micro and macro aspects in the form of Western economics. Application-oriented undergraduate colleges and research-oriented colleges and universities, which mainly cultivate professional talents with solid professional knowledge and strong practical ability. The main problems in the application of economics courses in applied undergraduate colleges are as followings.

\subsection{Low Integration with Teaching Objectives}

Because the economics course is theoretically strong and difficult to practice, almost all applied undergraduate colleges classify it as a theoretical class. In reality, applied undergraduate colleges basically have clear teaching objectives, and can focus on cultivating applied and innovative talents, but lack of corresponding teaching support in practical operations. For example, the theoretical content of the students in different majors is the same, and the practical application of case teaching is too small; in the case of continuous compression of the total class, the instructor will either explain in detail or simply explain it comprehensively; the content of the lecture does not take-into-account the professionalism of the students. Demand and existing knowledge base make it more difficult to organize teaching activities in combination with local economic and social development. These will lead to students' enthusiasm for learning, and the knowledge they have learned does not know how to apply it to reality.

\subsection{Teaching Method is Simple}

Modern teaching generally uses multimedia. Many teachers have gradually developed the "screen" Xuanke and they have left the multimedia courseware. It seems that they will not go to class. Multimedia courseware is only a tool for assisting teaching. It should be used according to the content of the lecture. At the same time, it should pay attention to the aesthetics of the courseware, not the full-screen text, and the color matching is not harmonious, which affects the effect of students' viewing. As far as the course of economics is concerned, the proper citation of multimedia courseware is conducive to the development of teaching, such as the presentation of some cases, the presentation of charts, etc., but this does not mean that the blackboard can be completely abandoned, the advantage of the book is to enable students Have enough time to digest knowledge and keep pace with the trainer's ideas. For the formulation of some formulas in economics, the depiction of representative figures is recommended.

\subsection{Teaching Material Problem}

The use of applied undergraduate economics textbooks is basically different from that of ordinary research universities. It is generally keen on national planning textbooks. The characteristics of such textbooks are theoretically deep and comprehensive, but the application of knowledge. There is a lack of aspects. Applied undergraduate textbooks should select or develop professional textbooks suitable for them. Local applied universities should encourage teachers to participate in the preparation of applied textbooks. In the system of selecting teaching materials, colleges and universities have corresponding system design. The common steps are the teaching materials for the instructors to be selected for the first time. They are discussed by the teaching and research section and agreed by the department, and finally reported to the Academic Affairs Office for review. However, in practice, the choice of teaching is often determined by the top-down command. The author observes that students in applied undergraduate colleges generally rely heavily on the textbooks used in class. Therefore, the impact of choosing appropriate textbooks on students is enormous. 


\section{Advantages of MOOC-based Economics Teaching}

The quality of teaching in colleges and universities is influenced by many factors, such as course content, teaching methods and student participation. The emergence of MOOC resources has improved the quality of classroom teaching to a certain extent.

\subsection{Broaden Teaching Content and Resources}

As all major universities in China are actively engaged in the construction of MOOC projects, more and more teachers and students are exposed to MOOC and applied. Some well-known MOOC sites have emerged in China: MOOC China, Chinese University MOOC and Mutu.com. On these websites, using economics MOOC resources, students in applied undergraduate colleges cannot only learn traditional microeconomics and macroeconomics in a relaxed and pleasant environment, but also independently study economics related courses, such as experimental economics. Public economics, transformation and emerging market economics, and resource economics. Students of different majors can selectively learn from MOOC according to their professional needs and personal interests. High-quality MOOC resources are generally famous teachers and teachers. They have certain cutting-edge and professionalism. Learners can learn the knowledge points that are difficult to reach in classroom teaching. Through the guidance of famous teachers, they can better grasp the main points of learning. Easily apply theory to practice.

\subsection{Rich Teaching Methods}

Under the background of the rapid development of information technology and the cultivation of applied and innovative talents, the economics teaching methods of applied undergraduate colleges need to be improved, and they cannot be crammed. MOOC combines traditional classrooms with online classrooms, with students as the center and teachers as the guiding role. The introduction of MOOC provides support for the application of undergraduate college teachers in teaching reform. Whether teachers participate in MOOC construction or use MOOC developed by others, they can stimulate teachers' thinking about teaching reform. In addition, the emergence of MOOC has also helped the implementation of the economic flip classroom. Flipping the classroom teaching mode is part of the big education movement, emphasizing the students to learn independently before class. In the classroom, the teacher fully communicates with the students on certain issues.

\subsection{Help Teachers and Students Interact}

In the classroom teaching of traditional economics, the effect of teacher-student interaction is poor. The so-called interaction basically stays in the teacher's question about economics, and the students answer passively. The instructor will go to the classroom for a few minutes and leave the classroom after class. There are few opportunities for communication outside the classroom. Students will not generally discuss the knowledge points of a class in the class QQ group or WeChat group. The design of the MOOC course basically involves participation in the course discussion, and there are clear number of requirements. Discussions between students and between teachers and students can be carried out here. At the same time, using the MOOC's course discussion area, it can solve to some extent that some students do not ask the teacher for embarrassment or fear.

\subsection{In Line with Student Learning Characteristics}

The teaching of economics courses based on MOOC resources truly reflects the student-centered teaching philosophy. Most of the courses in an applied undergraduate course last for 45 minutes or 50 minutes, with two or three consecutive classes. The time for students to concentrate is limited, especially in the case of a full-fledged economics lecture, and the general response teaching effect is poor. The MOOC video of economics is short and precise. For example, the MOOC video production requirements of Chinese universities should be controlled within 20 minutes, which is in line with the short and precise information of students' habits. As a useful supplement to classroom learning, MOOC learners can overcome the time and physical space limitations of classroom teaching by completing the content within a relatively limited time frame. 


\section{Common Problems in MOOC Teaching Practice}

The rise of MOOC has promoted the reform of traditional classroom teaching methods. The existing research shows that high-quality MOOC resources are deeply loved by students, and the teaching effect is obviously improved. However, MOOC also has some areas for improvement in teaching practice. Specifically, there are the following points:

\subsection{Poor Quality of Instructional Design}

Some college teachers have a misunderstanding of MOOC, thinking that the introduction of MOOC is to share a network teaching resource with students, simply arrange tasks and homework, or organize exams, completely ignore the interactive features of the MOOC platform. The theme of the MOOC discussion forum is mainly based on the curriculum learning class. The enthusiasm of learners to actively participate in interactive communication is not high, the proportion of teacher-student interaction is small, and the overall interaction quality is at a lower level. Some teachers did not provide detailed course descriptions for the relevant MOOC courses, nor did they classify the difficulty level, which is not conducive to students choosing courses according to their professional needs and interests. The existing evaluation mechanism of MOOC teaching effect only focuses on the quantity and results, such as how many times the job is to be done, whether the task is completed or not. As for the quality of assignments and tasks, there is a lack of authoritative evaluation. The lack of process evaluation also limits the formation of an overall evaluation of MOOC teaching effectiveness.

\subsection{Students Are Not Very Concerned}

The teaching language of MOOC resources is mainly in English, and the corresponding teaching resources in China are limited, which makes the students who are weak in English discouraged. Under the support of the education sector policy, major universities in China are also actively encouraging and promoting the construction of MOOC resources. Due to practical reasons such as limited investment and limited teaching resources, it is difficult for application-oriented undergraduate colleges to develop high-quality MOOC resources, which is not conducive to attracting students' attention and use to MOOC. In many cases, the builders of the MOOC project neglect the promotion and promotion of the built resources, and the teachers who teach the corresponding courses do not actively recommend the existing MOOC resources to the students. These are likely to cause embarrassing situations in which the MOOC construction in China's colleges and universities is not hot and the participation of students is not high.

\subsection{Low Completion Rate}

Students who have access to quality MOOC resources have benefited a lot, but the completion rate of the course is still very low. Studies have shown that only $5 \%$ of registered people can complete an online course in China and receive credits and certificates ${ }^{[6]}$. The reasons for the low completion rate of the course are: the learning of MOOC resources is autonomous, the pressure of no credits and graduation requirements, the learning can be terminated at any time; the time and energy are limited; the difficulty and language of MOOC consumes the interest of learners; And the attitude of the companion.

\section{Optimizing the Countermeasures of MOOC in the Teaching of Economics Courses}

MOOC's teaching of economics courses not only adds more high-quality teaching resources, but also considers and promotes the reform of teaching methods. How to make good use of MOOC and make full use of students' autonomy and enthusiasm for teachers and students, we need to explore and work from many aspects.

\subsection{Building High Quality Economic MOOC Resources}

High-quality economic MOOC resources are an important guarantee for the success of mixed learning. The existing economic MOOC resources are generally created by famous teachers and 
have strong theoretical, authoritative and professional nature. However, as the teaching of economics courses in applied undergraduate colleges, it should be different from research-based universities, and it should emphasize the application of theoretical knowledge. In view of the restrictions on the faculty and financial resources of individual application-oriented undergraduate colleges, especially private colleges and universities, it is possible to integrate resources within the framework of college alliances, and encourage different application-oriented universities to jointly build economic MOOC resources and gather their specialties. Thereby achieving joint construction and sharing and expanding influence.

\subsection{Designing Appropriate Classroom Teaching and MOOC Integration Model}

For economics courses, MOOC resources can be used as a preview, supplement or after-school test for classroom instruction. It is necessary for classroom teachers to focus on the requirements and suggestions for MOOC learning in the classroom. For example, which MOOC websites can students learn MOOC courses in economics, the content of each course is summarized, and what professional and basic students are suitable for learning. According to the specific situation, the application of undergraduate economics courses can adopt different integration modes. In the school's self-built economic MOOC conditions, students can complete the corresponding content through the MOOC platform, and participate in a series of assessment links, according to the assessment results to determine whether they are eligible to obtain the corresponding credits. The advantage of this is that it increases the students' attention to the MOOC and improves the completion rate of the course. Otherwise, the students do not make full use of the MOOC resources, and they also violate the original intention of the construction. For economic MOOC resources that are not self-built, students can be encouraged to use the MOOC platform to register their own studies. As long as they can obtain the corresponding credits and certificates as required, the instructor should give recognition.

\subsection{Enhanced MOOC Online and Offline Discussions}

In the course of economics, the interaction between teachers, students and students is an important part of in-depth study. Good communication enables students to promote each other and make learning more effective. In addition, teachers can get useful information from them, such as which knowledge points are difficult to understand, and whether there is any need for improvement in teaching methods. MOOC's online communication theme is appropriately enriched, and in addition to the course learning class, the teaching management class and the emotional communication of learners are added. Strengthen the construction and management of the MOOC discussion forum. The teaching assistant or the teaching teacher should actively participate in the interactive communication to improve the experience of the learner. Offline discussion is a useful supplement to online discussion. On the one hand, it promotes the generation and sharing of learning strategies through offline communication. On the other hand, it makes it easier for students to form a learning community, stimulate their learning motivation, and better complete the course learning.

\section{Acknowledgement}

Fund Project: The research results of the provincial-level quality project "MOOC and applied undergraduate course teaching reform" (No.: 2017jyxm0867)

\section{About the author:}

Min Zhou (1979-), male, Hefei City, Anhui Province, lecturer, research direction: Internet finance.

\section{References}

[1] Huang Xiaojie, Liu Zhixiu. Application of Statistical Methods in the Evaluation of MOOC-Assisted Teaching Effects[J]. Journal of China West Normal 
University,2016,37(3):316-319.

[2] Hao Lianke, Meng Yingying. Analysis of the Application Effect of College Mixed Learning Mode in MOOC Environment[J]. Journal of Tonghua Teachers College,2018,39(1):105-110.

[3] Tang Huiyun. Implementation Status and Effect Analysis of Network Sharing Course Based on MOOC Platform[J]. Journal of Taiyuan Urban Vocational and Technical College, 2017, (11): 147-149.

[4] Wang Sujun. Research on the Innovation of the Teaching System of Western Economics_-Based on the Innovative Application Talents Training Mode of Local Finance and Economics Colleges[J]. Journal of Hebei University of Economics and Business,2010,10(3):105-109.

[5] Zhou Xiaoyue, Tan Xinxin. Some Ideas on the Reform of Western Economics Course in Financial Mathematics_-Based on Questionnaire Survey Results[J]. Journal of Dalian University,2018,39(3).

[6] Zhang Hongyan, Yang Lixue. Analysis of the status quo and problems of MOOC research in China [J]. Development Learning Research, 2017, (6): 35-42. 